Проаналізовано вихрострумовий метод виявлення прихованих об'єктів та теоретично обтрунтовано можливість використання спектрального аналізу для розрізнення металів. Показано, що запропонований метод обробки сигналу дозволяе визначати тип металу в підгрупі кольорових металів. Наводяться структурна схема приладу, алгоритм обробки сигналу та результати експериментальних досліджень, які підтверджують можливість відрізнити мідь від золота чи срібла. Перевагою методу є дистанційний аналіз типу металу, з якого виготовлено приховані об'єкти

Ключові слова: Әихотомія, вихрострумовий металошукач, VLF металошукач, PI металочукач, струми Фуко, мікроконтролери

Проанализирован вихретоковый метод выявления скрытых объектов и теоретически обоснована возможность использования спектрального анализа для различения металлов. Показано, что предложенный метод обработки сигнала позволяет определять тип металла в подгруппе цветных металлов. Приводятся структурная схема прибора, алгоритм обработки сигнала и результать әкспериментальных исследований, подтверждающие возможность отличить медь от золота или серебра. Преимуществом метода является дистанционный анализ типа металла, из которого изготовлены скрытые объекты

Ключевые слова: дихотомия, вихретоковый металлоискатель, VLF металлоискатель, РІметаллоискатель, токи Фуко, микроконтроллеры

\section{APPLICATION OF SPECTRAL ANALYSIS FOR DIFFERENTIATION BETWEEN METALS USING SIGNALS FROM EDDY-CURRENT TRANSDUCERS}

\author{
A. A bramov y ch \\ Postgraduate student* \\ E-mal: osslo@ukr.net \\ V. P o d d u b n y
}

PhD, Associate Professor*

E-mail: vapoddubny@gmail.com

*Department of Radioengineering Devices and Systems National Technical University of Ukraine "Igor Sikorsky Kyiv Polytechnic Institute" Peremohy ave., 37, Kyiv, Ukraine, 03056

\section{Introduction}

The problem of detection of hidden metal objects in different media has always been important. Metal detectors, designed for searching for objects, and metal analyzers, intended for identification of material, from which a hidden object is made, are used for solution of this problem. Metal detectors are usually based on the vortex-current method for detection of the objects [1], which by their electrical or magnetic properties are different from the medium, in which hidden items are found. Metal detectors, as a rule, allow finding a metal object and carrying out its dichotomous (ferrous/non-ferrous) identification. Such a device cannot identify the type of non-ferrous or ferrous metal. The type of metal can be determined only visually, but for this, an object must be found and analyzed under laboratory conditions on special metal analyzers

There are several methods of such analysis [2]. The most common is the chemical method, based on decomposition of researched material into atoms and molecules and further exploration of the spectrum, obtained from constituent parts of an object. This is the most accurate method of analysis. But this method does not make it possible to determine composition of metal without laboratory tests.
Now chemical method is replaced by others, such as optical-emission, X-ray fluorescent, atomic-absorption, atomic-emission, etc. The most common of them are optical-emission and X-ray fluorescent analysis [3].

Optical-emission methods of analysis are used to study the structures, components, rough parts, etc. There are two types of the method: spark analysis and air-arc method. They are based on heating metal by electric field that appears when a spark or an arc are induced by a powerful laser or gas flame. The researched metal partly evaporates, passes through air or argon medium and is registered by a spectrometer. The composition of an object is determined by the radiation spectrum of each component of explored material.

Optical-emission instruments determine even minor impurities in metals, such as the amount of phosphorus, sulphur or carbon in ferrous metal. High accuracy of impurities' determining allows using them for certification analysis. The device is supplied with analytical programs, sewn into it, which significantly complicates analysis of alloy if its composition is not known even approximately.

$\mathrm{X}$-ray fluorescent analysis enables us to control the composition without significant damage to a research object. This type of devices is able to conduct analysis of up to a few dozen elements in alloys. Dimensions of a sample can 
be small enough, for example, shavings. The disadvantage of X-ray fluorescent devices can be the fact that they do not register elements with a number by order less than eleven in the Mendeleev table, which does not allow analysis of materials containing carbon, which applies to iron and steel. In addition, they are less accurate, and the surface of an object under investigation must be cleaned from paint and rust.

That is, this method also requires existence of a sample of metal and does not make it possible to determine its composition at the distance, without laboratory tests.

Therefore, the problem of identification and analysis of the composition of metal objects without their being damaged, including the ones hidden in another dielectric medium is relevant.

\section{Literature review and problem statement}

The problem of detecting hidden objects is largely solved with the use of (eddy)-current devices (ECD) - metal detectors. Metal detectors of VLF-type (Very Low Frequency detectors) and PI (pulse induction) detectors are the most common among ECD. The former are constructed based on transmission/reception of the tone signal. The latter operate with pulsed signals. They are inherently low frequency radio location stations [4]. In the modern market, ECD are represented by metal detectors, produced by companies Minelab, Fisher, Garret, AKA [5]. It should be noted that all devices perform the task of detecting hidden objects, and most of them - the task of analysis of the metal, from which an object is made, but they are limited to dichotomous analysis, division of material of an object into subgroups of ferrous or non-ferrous metals. Company-designers failed to realize the possibility to distinguish between metal objects within subgroups in their devices.

ECD of VLF-type solve the problem of dichotomous differentiation between metals (separation of a set of all metals into two subsets: ferrous and non-ferrous metals). That is, they solve the problem of detecting a hidden metal object and indicate whether it is made of ferrous or non-ferrous metal. They cannot distinguish between copper and aluminum or gold.

Existence of various metal trash in soil, as well as of rust on the surface of ferrous metals and a high level of mineralization of individual sections of soils result in frequent false actuation. In addition, it is not possible to use such ECD in confined spaces because while scanning, the search requires to move the antenna system in parallel to the studied surface.

ECD of PI (pulse induction) type enable us to find dielectric objects (for example, the foundation of a building or voids) in soil. But they cannot identify material of an object (metal, wood, plastic). This limits the use of ECD of PI type in archaeological and geophysical explorations and in search for hidden objects by power structures.

The best technical characteristics can be obtained by combining these techniques, which is proposed in [6].

Operation of ECD is based of phenomenon of excitement on the surface of a researched metal object of vortex currents [7], which appear as a result of interaction of electromagnetic field that is induced in them by radiation coil of the transmitting antenna. These currents induce secondary electromagnetic field, which is registered by the receiving antenna, processed by the electronic unit and transmitted to the indicator $[8,9]$.
Information about the studied object is in the amplitude, phase or frequency of the signal, received by the antenna, in this case, one of these parameters is informative, and the others are interfering. Amplitude, phase and frequency methods of signal processing are used in modern metal detectors for detection and analysis of informative parameters.

Amplitude method [6] is widely used to analyze a signal in case the informative factor is the amplitude of a signal and the interfering factor is the phase or frequency of the received signal. For this purpose, the amplitude detector is included in the structure of ECD. It monitors the amplitude of an input signal and supplies information to the indicator when reaching some threshold value. The indicator signals the existence of an object, as well as the metal it is made of: ferrous or non-ferrous. In this case, a change in the phase or frequency of a signal does not affect the readings of a metal detector. Most modern metal detectors just use metal identification by threshold level of a signal, which allows performing only dichotomous analysis.

Amplitude approach to detection of an informative signal has several disadvantages, the main of which is a large number of false actuations during search works in the section with lots of trash (mineralized soil, metal shavings, nails, and screws). A decrease is sensitivity of the device for minimization of the number of false actuations leads to loss of information about metal samples of small dimensions. The amplitude of a reflected signal depends on magnetization level of a hidden object. If two objects - magnetic (steel) and nonmagnetic (copper) lie next to each other, the signal from the magnetic object will be much larger than that from the nonmagnetic one. This is explained by the fact that the magnetization level of steel is seven times as high as the level of magnetization of copper and the latter will be impossible to detect. That is why ECD, based on vortex- current method of metal identification, do not enable us to determine the type of metal, if two samples from different metals are in close proximity to each other. Minimum distance between the objects that are possible to differentiate is close to half diameter of the receiving antenna.

The phase and frequency methods are applied at significant influence of an interfering factor on the amplitude of a signal. In the block diagram of ECD, which implements the mentioned methods, the phase or the frequency methods are used instead of the amplitude detector.

These two methods are generally used in devices of non-destructive control of parameters of metal objects [10].

On the basis of the phase method, paper [15] made an attempt to measure the initial phase of the signal, reflected from the studied object, to construct the metal analyzer. However, the author managed only to identify objects in terms of ferrous/non-ferrous, as well as to separate samples by dimensions. The phase measurement technique is also used in papers that involve creation of defectoscopes [16]. Overview of the goals and objectives of research papers has shown that the authors did not set the goal of creating a metal analyzer for remote identification of the metal type within one of the subgroups. It should be noted particularly that subject matters of the reports of the international conference on the issues of development and use of subsurface radar [17] indicate that the studies are aimed at increasing sensitivity, designing of new antennas, but there were no works involving creation of metal analyzers based on ECD.

The problem of identification of composition of metal hidden objects in dielectric (soil) media can be solved by 
(eddy)-current devices (ECD) [5], but to do this, it is necessary to refine the methods of processing the signals, received from ECD. That is why the problem of exploration of the vortex-current method, analysis of composition of detected metal objects and development of new methods, which allow identification of the metal type in the subgroup of non-ferrous metals, remains relevant.

\section{The aim and objectives of the study}

The aim of present research is to create a method that allows vortex-current devices to perform analysis of composition of an object in subgroups of ferrous or non-ferrous metals.

To accomplish the set goal, the following tasks had to be solved:

- to analyze vortex-current detection method and to substantiate the use of the spectral method for differentiation between metals;

- to develop and manufacture the device for research and the research procedure;

- to prove experimentally the possibility of using spectral analysis for detection and determining the composition of hidden metal objects;

- to determine merits of the spectral method of analysis for identification of hidden objects.

\section{Vortex-current method for detection of hidden objects, substantiation of spectral method of differentiation between metals}

The transmitting antenna of the vortex-current transducer induces primary electromagnetic field that is received by the antenna, tuned so that in the absence of metal objects between the receiving and transmitting antennas, at the inlet of the receiver the signal should be minimal.

If a metal object gets to operation area of the antennas, by the Faraday's law, variable electromagnetic field on the surface of an object induces electric current, which creates secondary electromagnetic field. Under the influence of the secondary electromagnetic field, the primary field changes and a signal occurs at the outlet of the receiving antenna. Electrical and magnetic properties of a hidden metal object affect the form of the received signal

The level of signal $U_{V D}$, which is excited by secondary electromagnetic field in the receiving antenna depends on electrical conductivity of material of the studied object $\sigma$ and on its magnetic permeability $\mu, U_{V D}=f(\sigma, \mu)$. As shown in [6]

$$
U=f\left(\varphi_{1}(x, \beta)\right)
$$

where

$$
\varphi_{1}(x, \beta)=\frac{\mu_{r}-\sqrt{x^{2}+j \beta^{2}}}{\mu_{r}+\sqrt{x^{2}+j \beta^{2}}}
$$

is the function of influence, $\beta=R_{3} \sqrt{\omega \mu_{a} \sigma}$ is the generalized parameter of vortex-current control (State Standard 24289$80), x=\lambda R_{p} \mu_{r}$ is the relative magnetic permeability of material of the studied object; $\mu_{\mathrm{a}}$ is the absolute magnetic permeability, $\mu_{a}=4 \pi \cdot 10^{-7} \mathrm{H} / \mathrm{m}, \sigma$ is the electric conductivity of material of the studied object, $\lambda$ is the parameter of integral transformation, $R_{p}$ is the radius of transmitting (probe) an- tenna, $j=\sqrt{-1}, \omega$ is the circular frequency of excitement of current. Information about the studied object is in the form of the signal.

Informative feature can be spectral density of signal $U_{V D}$ (its width by level of $40 \mathrm{~dB}$ and area under the envelope of spectrum), which is defined from the Fourier transformation

$$
S(f)=\int_{-\infty}^{\infty} U_{V D}(t) e^{-2 \pi i f t} \mathrm{~d} t
$$

Let us show the difference in spectra of signals, received from different metals. For simplicity, we assume that all parameters, besides magnetic permeability and electric conductivity, are constant. Then the spectrum of the output signal depends only on function of influence $\varphi_{1}(x, \beta)$.

Let us calculate its value for two metals - steel and copper. As it is known [2], relative permeability of steel $\mu_{\mathrm{r}}=100$, and of copper $\mu_{r}=1$, iron conductivity (steel) $\sigma=0.769 \cdot 10^{3} \mathrm{~cm} / \mathrm{m}$ and of copper $\sigma=50.5 \cdot 10^{3} \mathrm{~cm} / \mathrm{m}$ Then modules $\left|\varphi_{\text {1steel }}(x, \beta)\right|=0,836$ and $\left|\varphi_{\text {1copper }}(x, \beta)\right|=1$.

As we can see, the difference in values of parameter $\varphi_{1}(x, \beta)$ for steel and copper is essential, and, accordingly, the difference in areas under envelopes of spectra of the signals, received from the studied objects, must be also essential. This will make it possible to identify the type of metal.

\section{Block diagram of the designed device and results of research into metal hidden objects}

To prove the proposed hypothesis, we designed the mockup of the (eddy)- current transducer, which allowed conducting experiments on detection of metal objects, made of ferrous and nonferrous metals, and proved the possibility of using the spectral method for identification of the type of metal.

The structural scheme of ECD is shown in Fig. 1, the appearance of the laboratory mockup of ECD is shown in Fig. 2. The transducer consists of the antenna system (transmitting 1 and receiving 4 antennas), pulsed generator of low-frequency signal 2, unit of signal amplification and processing 5 , generator of tact pulses 7 , micro-control unit 3 and indicator 6 .

Generator of low-frequency signal 2 forms pulsed signals that enter transmitting antenna 1 and induce electromagnetic field in the studied environment. Due to electromagnetic induction, Foucault currents, which distort primary electromagnetic field, emerge on the surface of the studied object.

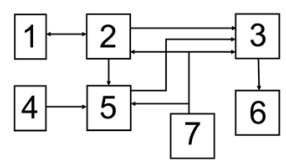

Fig. 1. Block diagram of (eddy)-current transducer

Changes in the field are registered by receiving antenna 4, amplified and pre-processed in unit 5. Synchronization between nodes of the ECD is provided by tact pulse generator 7. After processing, the signal enters micro-control unit 3. In it, the signals, received from the studied samples, are compared with the reference signals, stored in the memory unit of the device. The result of comparison is delivered to indicator 6 .

ECD is based on two microcontrollers AVR Atmega32. The first one controls operation of the vortex-current unit, 
the other provides for conversion of measured data to the required format for further transmission to the personal computer (PC). Laptop HP 4540s is used as the indicator. Application package MATLAB for signals processing was installed in it. In its environment, calculation of spectrum density [11] is carried out by means of the developed normalization program and internal program of the package of spectral transformations. Information about the reflected signal is transmitted by 8-bit packets from the laboratory mockup to the PC. USB-port. is used for connection. The dynamic range of the microcontroller's ACD is about $48 \mathrm{DB}$.

The antenna system consists of two frame magnetic antennas [12], located coaxially in one plane. The external antenna is used for radiation of electromagnetic field, and the internal - for reception of this signal.

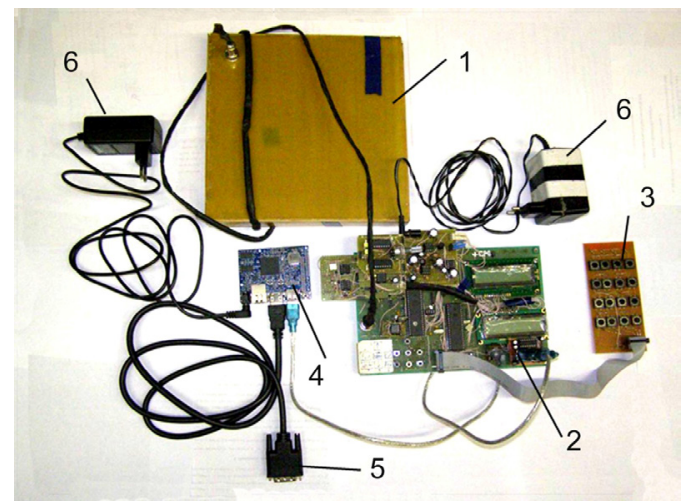

Fig. 2. General view of the lab ECD mockup: 1 - antenna unit; 2 - receiving-transmitting unit; 3 - keyboard; 4 - information processing board; 5 - connector for laptop; 6 - power supply unit

Characteristics of antennas and their design parameters are given in Table 1.

Table 1

\section{Structural characteristics of antennas}

\begin{tabular}{|c|c|c|}
\hline Characteristics & Transmitting & Receiving \\
\hline Wire diameter, $\mathrm{mm}$ & 0.33 & 0.22 \\
\hline Height of antenna, $\mathrm{mm}$ & 5 & 6 \\
\hline Number of coils, $\mathrm{w}$ & 85 & 275 \\
\hline Number of wire layers, $\mathrm{n}$ & 5. & 12 \\
\hline $\begin{array}{c}\text { Internal diameter of } \\
\text { frame } d_{r}, d_{t \mathrm{a}} \mathrm{mm}\end{array}$ & 162 & 81 \\
\hline Inductivity, $\mathrm{mH}$ & 3.87 & 13.14 \\
\hline
\end{tabular}

Technical characteristics of ECD are the following: frequency of probe pulses $-6.6 \mathrm{kHz}$, relative pulse duration -10 , signal power in the transmitting antenna $-1 \mathrm{~W}$, sensitivity of the receiving tract $-48 \mathrm{~dB}$.

Experimental research was carried out at two stages.

The first stage included research into possibility of dichotomous identification of metals by feature ferrous/nonferrous and identification of the type of metal in the subgroup of nonferrous.

The second included research into possibilities of detection of ferrous and nonferrous metals, if they are close to each other and identification of the type of metal on the noise background (various metal trash).

At the first stage of the research, the impact of interfering factors (mineralized soil, metal trash and others) was reduced to minimum, that is why the experiments were car- ried out in air medium, i. e. there were no dielectric and conductive materials between the antenna and research samples.

The object samples, made of ferrous metal (steel) and non-ferrous metals (copper, aluminum, etc.), were examined. The samples have dimensions smaller than the diameter of the receiving antenna and were of the same volume. Their geometric dimensions included $25-\mathrm{mm}$ diameter and 3-mm thickness.

For every particular sample of metal, 100 measurements were performed for a set of statistical data with probability of obtaining reliable result of 0.95 [13].

Signals, induced by secondary electromagnetic field in the receiving antenna and amplified in unit 5, are different for various metals (steel and copper) by amplitude, shape and duration. The amplitude of the steel-induced signal is much larger than the amplitude of the copper-induced signal (Fig. 3), which is explained by different electrical and magnetic properties of the metals. This leads to necessity to normalize the signal by amplitude.

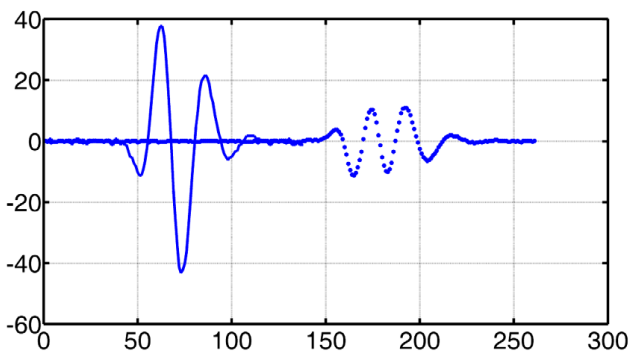

Fig. 3. Shape of the signal, induced in the receiving antenna by secondary electromagnetic field, for various metals (continuous line - copper, dot line - steel)

In addition, the rate of scanning by the antenna system over the sample can vary and is determined by skills and physiological features of an operator, who conducts scanning of a hidden object.

Time discrepancy is particularly strongly pronounced, if the search is going on under the field condition, because the operator cannot scan with the search antenna over the studied surface at the same rate. The duration of a signal depends on velocity of passage of the search antennas over a hidden object, which should be the same throughout the whole stage of the search for metal samples, however, this does not happen under actual conditions of ECD operation. That is why the high-speed effect occurs, which involves a change in duration of passing of the antenna system over a hidden object and, accordingly, a change in duration of ECD signal, which requires normalization of a signal by duration. The distance between two signal maxima is used as the normalization parameter.

The duration of the signal, obtained from the first scanning of an object, is accepted as reference duration. All following signals are normalized by duration in accordance with it. At this stage, the signal digitization is carried out and duration of the reference signal between two maxima is measured. Signal is processed by means of mathematical package MATLAB, [11,12], installed on HP 4540s and connected to ECD. To determine the maxima of the received signal, we used a specially designed algorithm of averaging by three points (Fig. 4), which shows how points $t 1-t 3$ are located at sequential fitting of signal amplitude value. 
The algorithm is based on measurement of the highest amplitude value by three points $(t 1, t 2, t 3)$ by the method of sequential fitting of all signal values. The amplitude in middle point $t 2$ was chosen as evaluation.

The variants of sharp and gentle maximum are possible.

We will consider the case of sharp maximum. In this case, amplitude at point $t 2$ is larger than amplitude of the following and the previous points. The number of iterations is accepted as the number of the sought for maximum.

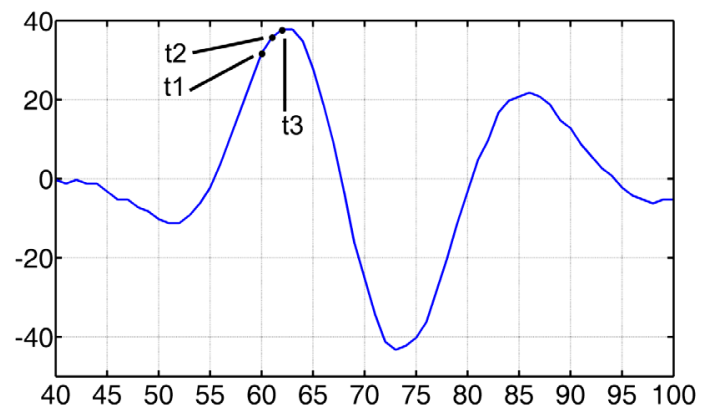

Fig. 4. Process of matching points $t 1-t 3$ when determining maximum value of signal amplitude

At sloping maximum, amplitude at point $t 2$ is larger than amplitude at point $t 1$ and equal to amplitude at point $t 3$ within several iterations of fitting of signal discrete. In this case, the number of the last iteration at equality of $t 2$ and $t 3$ is accepted as the sought for maximum.

The algorithm of the search for the signal maximum, which is used in the software, is listed in Fig. 5. Duration of scanning was determined as the time interval between two maxima and is considered as a reference. Subsequently, duration of signals for new samples was reduced to duration of the reference signal.

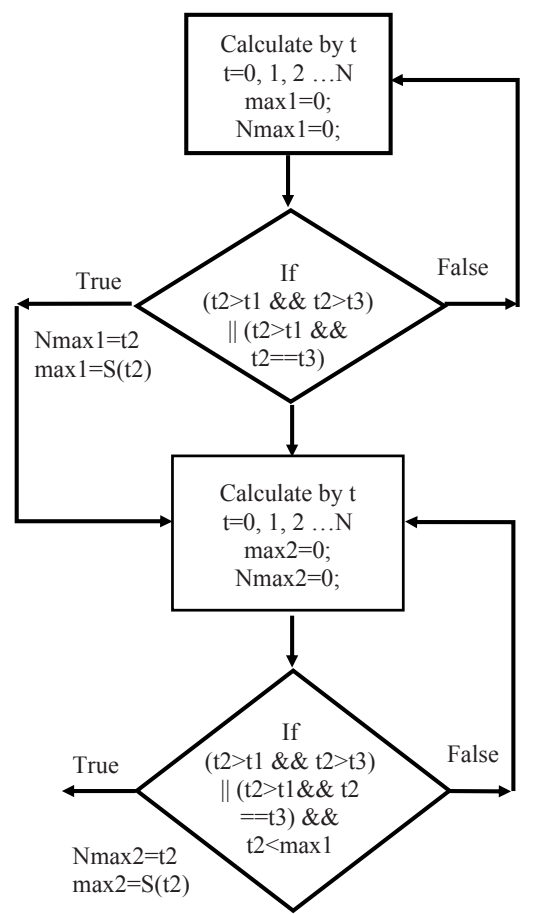

Fig. 5. Algorithm of the search for a signal's maxima

The duration of the signal, received at first scanning of an object was accepted as reference of duration. Normal- ization of a signal both by amplitude and by duration was carried out using the software, installed on HP 4540s.

The typical forms of the signals, normalized by amplitude and duration of signals for the examined samples of ferrous and non-ferrous metals are shown in Fig. 6 ( $a$ - steel, $b$ - copper, $c$ - aluminum).
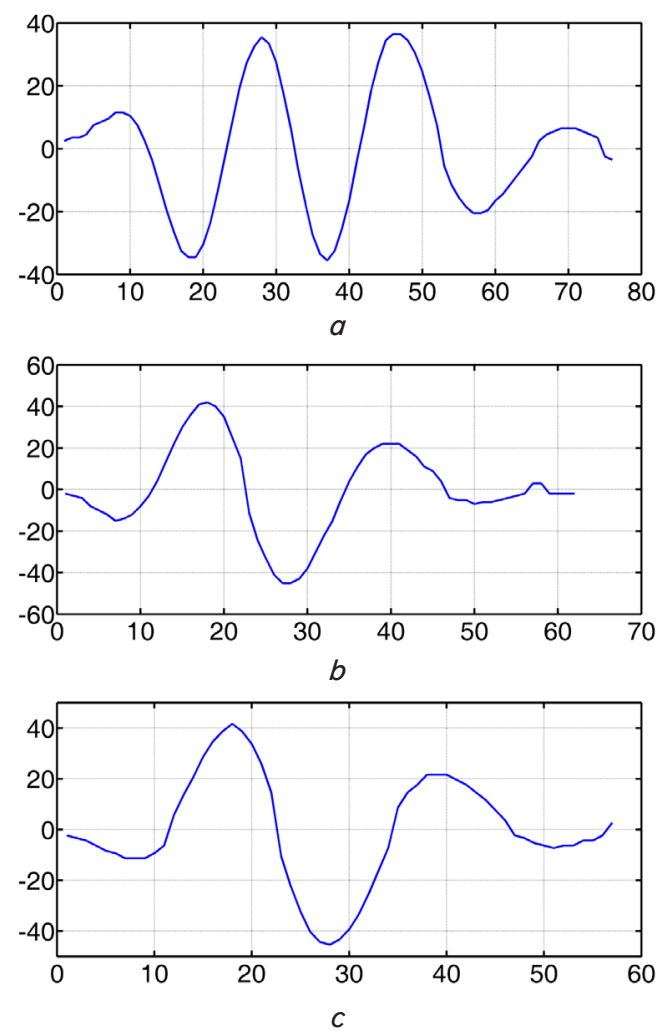

Fig. 6. Typical shapes of signals for samples, made of various metals: $a$-steel, $b$ - copper, $c$ - aluminum

It is quite difficult to compare such signals visually. That is why additional signal processing is required, which allows identification of characteristics of a signal, which carry information about a hidden object.

Paper [14] proposed the spectral method of signal processing, which implies that spectral density $S^{*}(f)$. $S^{\prime \prime}(f)$ is used as the informative parameter of $\mathrm{U}_{\mathrm{VD}}$ [6] and a signal itself is dependent on $\mu_{v}, \mu_{a}, \sigma$ and in frequency region is described by expression $S^{*}(f)=S(f) R(f)$, where $R(f)$ and $S(f)$ are the attenuation factor when passing through multi-layer medium, in which the studied sample is found.

The averaged normalized values of measuring signals from different samples were passed on to PC for calculation of spectral characteristics of the signal. Results of measurements of the main spectral characteristics, obtained for scanning time (one iteration of the antenna system), are shown in Fig. 7 (Fig. 7, $a$-steel, Fig. 7, $b$ - copper, Fig. 7, $c-$ aluminum) and in Table 2.

Percentage difference of parameters between different metals is shown in Table 3.

Difference of areas under envelopes of spectrum and bands for metal pairs copper - lead and copper - gold is insignificant and does not allow us with high probability to identify metals without spectroanalyzers with high separative power. This requires development of high-precision methods for spectrum analysis or development of other (additional) methods of processing of measurement results. 

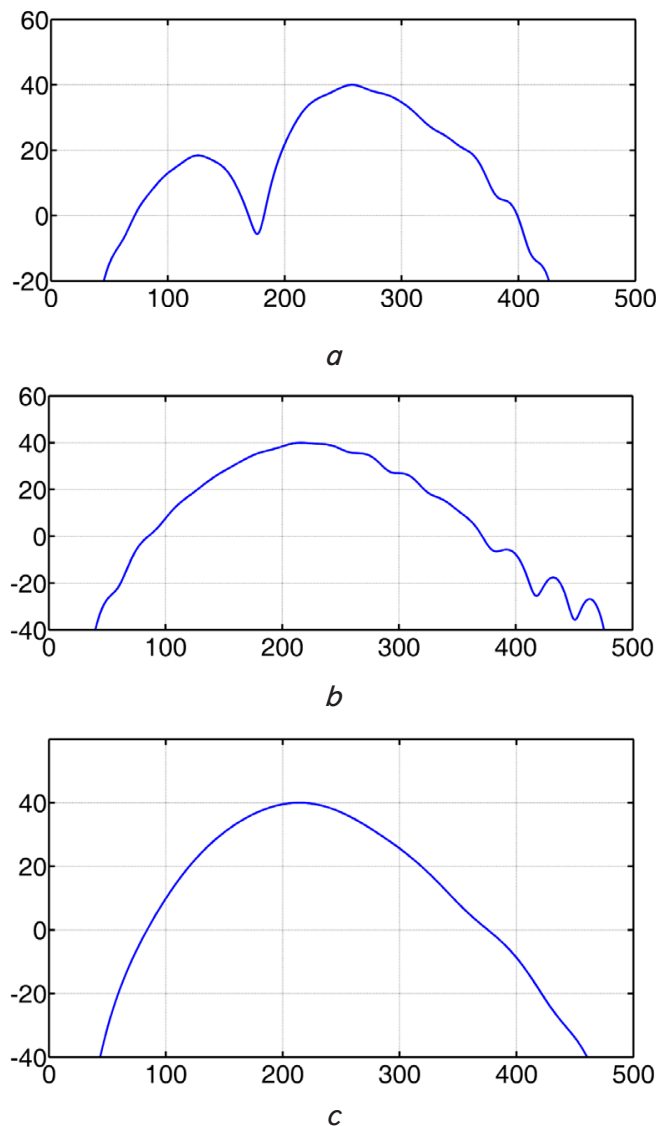

Fig. 7. Spectral densities of signals from the studied samples: $a$ - steel, $b$ - aluminum, $c$ - copper

Table 2

Parameters of basic spectral characteristics of the studied samples

\begin{tabular}{|c|c|c|}
\hline Metal & $\begin{array}{c}\text { Width of spectrum } \\
\text { by level }-40 \mathrm{~dB}(\mathrm{~Hz})\end{array}$ & $\begin{array}{c}\text { Area under envelope } \\
\text { of spectrum }(\mathrm{dB} \cdot \mathrm{Hz})\end{array}$ \\
\hline Steel & $72 \ldots 410$ & 7,710 \\
\hline Copper & $112 . .490$ & 10,026 \\
\hline $\begin{array}{c}\text { Two metals } \\
\text { (steel and copper) }\end{array}$ & $130 \ldots 418$ & 7,400 \\
\hline Silver of 868 purity & $110 \ldots 465$ & 9,227 \\
\hline Gold of 900 purity & $112 \ldots 480$ & 9,464 \\
\hline Lead & $110 \ldots 480$ & 9,776 \\
\hline
\end{tabular}

Table 3

Calculated difference of parameters between copper and other metals

\begin{tabular}{|c|c|c|}
\hline Compared metals & $\begin{array}{c}\text { Difference in areas } \\
\text { under envelopes }\end{array}$ & Difference in bands \\
\hline Copper and silver & $7.8 \%$ & $4.48 \%$ \\
\hline Copper and gold & $5.6 \%$ & $1.67 \%$ \\
\hline Copper and titanium & $15.8 \%$ & $11.96 \%$ \\
\hline Copper and lead & $2.5 \%$ & $1.99 \%$ \\
\hline Copper and aluminum & $8.927 \%$ & $7.8 \%$ \\
\hline
\end{tabular}

The second stage of the study involves the placement of two samples of various metals at a distance of less than half diameter of the antenna system (next to it). Spectral characteristics of the signal, recorded in this case are shown in Fig. 8.

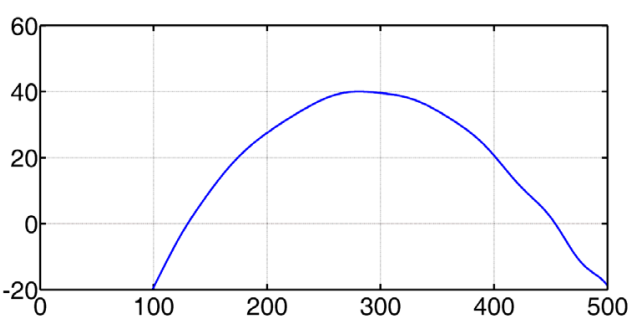

Fig. 8. Spectrum of signal, received from steel and copper samples that are found next to each other

Spectra of signals from samples of various metals are superimposed on one another.

When working with trashed medium, the spectrum of a signal is similar to the one, shown in Fig. 6, which allows us to identify the type of metal of the sample and determine the type of trash. Thus, it was experimentally established that the ECD mockup confidently identifies existence of a copper coin in a pile of trash of non-ferrous metal in the ratio of masses of 10 to 1.

\section{Discussion of results of studying hidden objects by a spectral method}

An analysis of spectral characteristics showed that spectral density for ferrous (steel $-4.22 \mathrm{~dB} \cdot \mathrm{Hz}$ ) and non-ferrous metals (aluminum - $5.85 \mathrm{~dB} \cdot \mathrm{Hz}$, copper $-5.81 \mathrm{~dB} \cdot \mathrm{Hz}$ ) essentially differs from each other, while in the subgroup of non-ferrous metals, one metal differs from another to significantly less extent (1.67...11.96\%).

It makes possible to perform dichotomous differentiation between ferrous and non-ferrous metals with high reliability. In the presence of highly sensitive spectroanalyzers (measurement error does not exceed $1 \%$ ), which can be realized by the program, one can perform identification of metals in the subgroup of non-ferrous metals. To do this, it is necessary to create a reference base for metals and write it down into memory of the micro-control unit. After comparing the spectrum of the signal, received from an unknown sample, with the reference spectra and its coincidence with the one from the database, it is possible to identify metal, from which a hidden object is made.

It should be emphasized that, unlike other methods of identification, the spectral method enables us to distinguish between metals that are at the distance of less than half diameter of the antenna system (next to it). Spectral characteristics of the signal, recorded for two samples of steel and copper, which are nearby, have the extended spectrum in comparison with pure metals. As you might see, the informative part of the spectrum is within the range of $83 \ldots 290 \mathrm{~Hz}$.

The task of metal identification in this case is reduced to determining of getting of spectra of reference samples to the spectrum, calculated by the informative signal. The ratio between the areas under envelopes of spectra of signals of measured and reference spectra indicates percentage content of particular metal in a hidden object.

Thus, the use of spectral method for identification of metals enables us to create a vortex-current transducer, which has a new quality - distant analysis of the type of metal.

The present research was carried out in homogeneous dielectric medium (air), but allowed us to prove experimentally the hypothesis about the possibility of using the methods of 
spectral analysis for identification of the type of metal in the subgroup of non-ferrous metals. They are part of the study, performed in the framework of the initiative scientific research "Research into possibilities of using spectral analysis of signals of a metal detector for dichotomous identification of the type of metal (State registration N. 0216U0007428). In the future, it is planned to perform similar research into non-homogeneous dielectric media and to use the results for designing new devices for remote identification of hidden metal objects.

\section{Conclusions}

1. A (eddy)-current method for detection of hidden metal objects was analyzed. It was indicated that amplitude of the output ECD signal is determined by conductivity of the material of a hidden object and its magnetic permeability. It was shown that the informative feature could be the spectral density of a signal.

2. We designed and fabricated a mockup of the (eddy)-current device, the features of which include modularity, which, if necessary, makes it possible to replace quickly each of the modules. A special feature of the designed mockup is normalization of signals by the first scanning and possibility of quick readjustment of operating algorithms. The developed algorithm of normalization of signals allows an operator to choose freely a scan mode and correctly compare ECD signals with reference signals.

3. The designed ECD layout enabled us to conduct experimental research of spectra of objects from different metals. To compare metals, the band and the area under the envelopes of signal spectrum were analyzed. Research results show that it is possible to distinguish easily between the spectra of ferrous metals and those of non-ferrous metals. With sensitive spectroanalyzers, we can identify metals in these subgroups with error of measurement not exceeding $1 \%$. This proved the possibility of using spectral methods both for dichotomous analysis of hidden metal objects and for determining the type of metals in the sub-group of non-ferrous metals.

4. It was shown that the advantage of the spectral method for analysis of signals of the vortex-current converter is identification of hidden objects by the type of metal. The use of spectral methods for detection of hidden metals offers a new property - distant analysis of detected metal objects.

\section{References}

1. Ihamouten, A. Electromagnetic dispersion estimated from multi-offset, ground-penetrating radar [Text] / A. Ihamouten, X. Dérobert, G. Villain // Proceedings of the XIII Internarional Conference on Ground Penetrating Radar. - 2010. doi: 10.1109/ icgpr.2010.5550085

2. Gornaya enciklopediya. Vol. 2 [Text] / E. A. Kozlovskiy (Ed.). - Moscow: Sovetskaya enciklopediya, 1986. - 575 p.

3. Van Sprang, H. A. Fundamental parameter methods in XRF spectroscopy [Text] / H. A. van Sprang // Advances in X-ray Analysis. - 2000. - Vol. 42.

4. Obiazi, A. M. O. Implementing a Robust Metal Detector Utilizing the Colpitts Oscillator with Toroidal Coil [Text] / A. M. O. Obiazi, F. I. Anyasi, O. Jacdonmi, P. A. Otubu, I. Abhulimen // Journal of Engineering and Applied Sciences. - 2010. - Vol. 5, Issue 2. P. 56-63. doi: 10.3923/jeasci.2010.56.63

5. Pravda, V. I. Heoradary [Text] / V. I. Pravda, O. D. Mrachkovskyi, A. O. Abramovych // Visnyk natsionalnoho universytetu «Lvivska politekhnika». Seriya: Radioelektronika ta telekomunikatsyi. - 2015. - Issue 818. - P. 49-54.

6. Abramovych, A. O. Radiolokatsiino-vykhrostrumovyi radar [Text] / A. O. Abramovych // Visnyk NTTU «KPI». Ser: Radiotekhnika. Radioaparatobuduvannia. - 2014. - Issue 57. - P. 77-82.

7. Habarov, V. B. Struktura elektromagnitnogo polya, izluchennogo podzemnym peredatchikom s ramochnoy antennoy, s uchetom blizhney zony rasprostraneniya radiovoln [Text] / V. B. Habarov // Radiotekhnika. - 2005. - Issue 3. - P. 80-83.

8. Shcherbakov, G. N. Uvelichenie predel'noy glubiny obnaruzheniya lokal'nyh ferromagnitnyh ob'ektov v tolshche provodyashchih ukryvayushchih sred metodom distancionnogo parametricheskogo podmagnichivaniya [Text] / G. N. Shcherbakov // Radiotekhnika. - 2005. - Issue 12. - P. 42-45.

9. Shcherbakov, G. N. Vybor elektromagnitnogo metoda zondirovaniya dlya poiska ob'ektov v tolshche ukryvayushchih sred [Text] / G. N. Shcherbakov // Radiotekhnika. - 2005. - Issue 3. - P. 77-79.

10. Nerazrushayushchiy kontrol'. Vol. 3 [Text] / V. V. Suhorukov (Ed.). - Moscow: Vyssh. shk., 1992. - 312 p.

11. Ayficher, E. Cifrovaya obrabotka signalov. Prakticheskiy podhod [Text] / E. Ayficher, B. Dzhervis. - Moscow: Vil'yams, $2004 .-992$ p.

12. Jol, M. H. Ground Penetrating Radar Theory and Applications [Text] / H. M. Joy. - Oxford GB.: Elsevier B.V., 2009. - 544 p.

13. Rumshiskiy, L. Z. Matematicheskaya obrabotka rezul'tatov eksperimenta [Text] / L. Z. Rumshiskiy. - Moscow: Nauka, Glav. red. fiz-mat. lit., 1971. - $192 \mathrm{p}$.

14. Abramovych, A. O. Dykhotomichne rozriznennia metalu na chornyi-kolorovyi za dopomohoiu spektralnoho analizu [Text]/ A. O. Abramovych, O. D. Mrachkovskyi, V. Yu. Furmanchuk // Visnyk Zhytomyrskoho derzhavnoho tekhnolohichnoho universytetu. Ser.: Tekhnichni nauky. - 2017. - Issue 1 (79). - P. 48-51.

15. Svatoš, J. Advanced Instrumentation for Polyharmonic Metal Detectors [Text]: PhD Thesis / J. Svatoš. - Prague, 2015. - $121 \mathrm{p}$.

16. Bazhenov, V. G. Metod i apparatura dlya izmereniya napryazhennosti elektricheskih poley pri geologo-geofizicheskih issledovaniyah [Text] / V. G. Bazhenov, N. A. Yakimchuk, S. V. Gruzin, I. S. Pidlisna // Zb. nauk. prats Teoretychni ta prykladni aspekty heoinformatyky. - 2014. - P. 17-30.

17. Kang, W. A study of antenna configuration for bistatic ground-penetrating radar [Text] / W. Kang, C. R. Kim, J. H. Kim, S. G. Park, S. J. Cho, J. S Son, K. W. Kim // 2016 16th International Conference on Ground Penetrating Radar (GPR). - 2016. doi: 10.1109/ icgpr.2016.7572697 